\title{
Food perception without ingestion leads to metabolic changes and irreversible developmental arrest in C. elegans
}

\author{
Rebecca E. W. Kaplan', Amy K. Webster ${ }^{1}$, Rojin Chitrakar ${ }^{1}$, Joseph A. Dent ${ }^{2}$ and L. Ryan Baugh ${ }^{1 *}$ (D)
}

\begin{abstract}
Background: Developmental physiology is very sensitive to nutrient availability. For instance, in the nematode Caenorhabditis elegans, newly hatched L1-stage larvae require food to initiate postembryonic development. In addition, larvae arrested in the dauer diapause, a non-feeding state of developmental arrest that occurs during the L3 stage, initiate recovery when exposed to food. Despite the essential role of food in C. elegans development, the contribution of food perception versus ingestion on physiology has not been delineated.
\end{abstract}

Results: We used a pharmacological approach to uncouple the effects of food (bacteria) perception and ingestion in C. elegans. Perception was not sufficient to promote postembryonic development in L1-stage larvae. However, L1 larvae exposed to food without ingestion failed to develop upon return to normal culture conditions, instead displaying an irreversible arrest phenotype. Inhibition of gene expression during perception rescued subsequent development, demonstrating that the response to perception without feeding is deleterious. Perception altered DAF-16/FOXO subcellular localization, reflecting activation of insulin/IGF signaling (IIS). The insulin-like peptide daf-28 was specifically required, suggesting perception in chemosensory neurons, where it is expressed, regulates peptide synthesis and possibly secretion. However, genetic manipulation of IIS did not modify the irreversible arrest phenotype caused by food perception, revealing that wild-type function of the IIS pathway is not required to produce this phenotype and that other pathways affected by perception of food in the absence of its ingestion are likely to be involved. Gene expression and Nile red staining showed that food perception could alter lipid metabolism and storage. We found that starved larvae sense environmental polypeptides, with similar molecular and developmental effects as perception of bacteria. Environmental polypeptides also promoted recovery from dauer diapause, suggesting that perception of polypeptides plays an important role in the life history of free-living nematodes.

Conclusions: We conclude that actual ingestion of food is required to initiate postembryonic development in C. elegans. We also conclude that polypeptides are perceived as a food-associated cue in this and likely other animals, initiating a signaling and gene regulatory cascade that alters metabolism in anticipation of feeding and development, but that this response is detrimental if feeding does not occur.

Keywords: Insulin, IGF, Perception, C. elegans, Diapause, L1 arrest, Food signal, Lipid metabolism

\footnotetext{
* Correspondence: ryan.baugh@duke.edu

'Department of Biology, Duke University, Box 90338, Durham, NC 27708-0338, USA

Full list of author information is available at the end of the article
}

(c) The Author(s). 2018 Open Access This article is distributed under the terms of the Creative Commons Attribution 4.0 International License (http://creativecommons.org/licenses/by/4.0/), which permits unrestricted use, distribution, and reproduction in any medium, provided you give appropriate credit to the original author(s) and the source, provide a link to the Creative Commons license, and indicate if changes were made. The Creative Commons Public Domain Dedication waiver (http://creativecommons.org/publicdomain/zero/1.0/) applies to the data made available in this article, unless otherwise stated. 


\section{Background}

Perception of food affects metabolism and development in a variety of animals. Several observations suggest that sensory perception of food can regulate metabolism. For example, humans release insulin in response to the sight and smell of food [59]. Loss of olfactory neurons in mice reduces obesity and insulin resistance, and enhancing olfactory acuity does the reverse [55]. Blocking olfaction in Drosophila alters metabolism and extends lifespan; conversely, the longevity-extending effects of dietary restriction are partially reversed by exposure to food odors [41]. Likewise, in Caenorhabditis elegans sensory perception of a water-soluble "food signal" affects development of dauer larvae, a form of diapause as an alternative third larval stage [27], and perception of food also affects lifespan [1, $3,33,39]$. However, the molecular cues that are sensed and their specific effects on organismal signaling and gene regulation are not well understood in any system.

C. elegans L1-stage larvae hatch in a state of developmental arrest ("L1 arrest" or "L1 diapause") and require food to initiate development [8]. Insulin/IGF signaling (IIS) is a key regulator of L1 arrest $[11,26]$. During starvation, $d a f-16 /$ FOXO promotes L1 arrest by inhibiting development-promoting pathways [11, 35]. Feeding upregulates activity of the insulin-like peptides daf-28, ins-6, and ins-4, among others, which act as putative agonists for the only known insulin/IGF receptor $d a f-2$ [17]. daf-2/InsR signaling activates a conserved phosphoinositide 3-kinase (PI3K) cascade to antagonize DAF-16 by preventing its nuclear translocation, thereby promoting development [36, 42, 47, 49]. daf-28, ins-6, and ins -4 are also critical to regulation of dauer development $[18,40]$, a form of developmental arrest that occurs in L3-stage larvae and is distinct from L1 arrest [8]. Together with their role in regulating L1 development, regulation of dauer development indicates that these insulin-like peptides are atop the organismal regulatory network governing postembryonic development. However, how these important insulin-like peptides are regulated in response to nutrient availability is unknown. IIS governs postembryonic development in insects as well $[12,15,16,53]$, suggesting that mechanisms mediating environmental influence on insulin-like peptide synthesis and secretion have broad significance.

Feeding in C. elegans is mediated by pumping of the neuromuscular organ called the pharynx [6]. The drug ivermectin paralyzes the pharynx by activating glutamate-gated chloride channels containing $\alpha$-type channel subunits, increasing chloride conductance and inhibiting cellular depolarization $[5,19,20,63]$. Several genes encoding glutamate-gated chloride channels in C. elegans, including $a v r-14, a v r-15$, and $g l c-1$, confer sensitivity to ivermectin, but simultaneous mutation of all three of these genes produces substantial ivermectin resistance [21].
Here we used ivermectin to prevent feeding in C. elegans L1 larvae exposed to food. We show that perception of food without ingestion significantly alters gene expression and activates IIS but is not sufficient to initiate postembryonic development. To the contrary, perception without ingestion makes developmental arrest irreversible. We show that starved worms sense polypeptides in their environment as a food cue, likely in anticipation of feeding.

\section{Results \\ Perception of food without ingestion renders developmental arrest irreversible}

We used ivermectin to prevent feeding in order to uncouple the effects of food perception from ingestion. To limit effects of the drug outside the pharynx, we started with a highly ivermectin-resistant strain, the quadruple mutant avr-14(vu47); glc-3(ok321) avr-15(vu227) $g l c-1$ (pk54) [21, 32], and rescued avr-15 with a myo-2 promoter for pharynx-specific expression. We made two versions of the strain with two different markers for analysis of L1 development: AJM-1::GFP to examine lateral epidermal seam cells and Phlh-8::GFP to examine the M-cell lineage. After making our primary observations with these transgenic strains in the quadruple mutant background, we used a wild-type background to facilitate genetic analysis of the phenotypes we discovered (see "Methods").

Throughout this study, most experiments follow the basic setup seen in Fig. 1a. We prepared embryos by hypochlorite treatment of gravid adults and cultured them in either ivermectin or control (DMSO) conditions without food for $24 \mathrm{~h}$ where they hatch and enter L1 arrest. Various types of food or other substances were then added (vertical dashed line in Fig. 1a), and worms were typically analyzed $1 \mathrm{~h}$ or $24 \mathrm{~h}$ after this addition. To determine if ingestion was occurring, fluorescent beads were added to the cultures and worms were examined. Critically, fluorescent beads were not ingested in the ivermectin plus food (E. coli HB101) conditions (Additional file 1: Figure S1A). For initial characterization of the effects of food perception without ingestion, worms were exposed to experimental conditions for $24 \mathrm{~h}$, then plated in standard laboratory conditions (on plates with E. coli OP50 but no ivermectin) and allowed to recover for 3 days. Worms exposed to ivermectin plus food failed to recover, remaining arrested in the L1 stage, while the controls recovered completely (Fig. 1b). That is, ivermectin treatment alone did not cause an irreversible arrest, but ivermectin plus food did. This striking phenotype was further characterized with a time series, revealing a near complete effect within about $8 \mathrm{~h}$ of exposure (Fig. 1c). Recovery to the L4 stage was chosen as an easy stage to reliably score. Though $24 \mathrm{~h}$ exposure generally rendered larvae capable of negligible if any growth, earlier time points associated with incomplete penetrance were associated with 


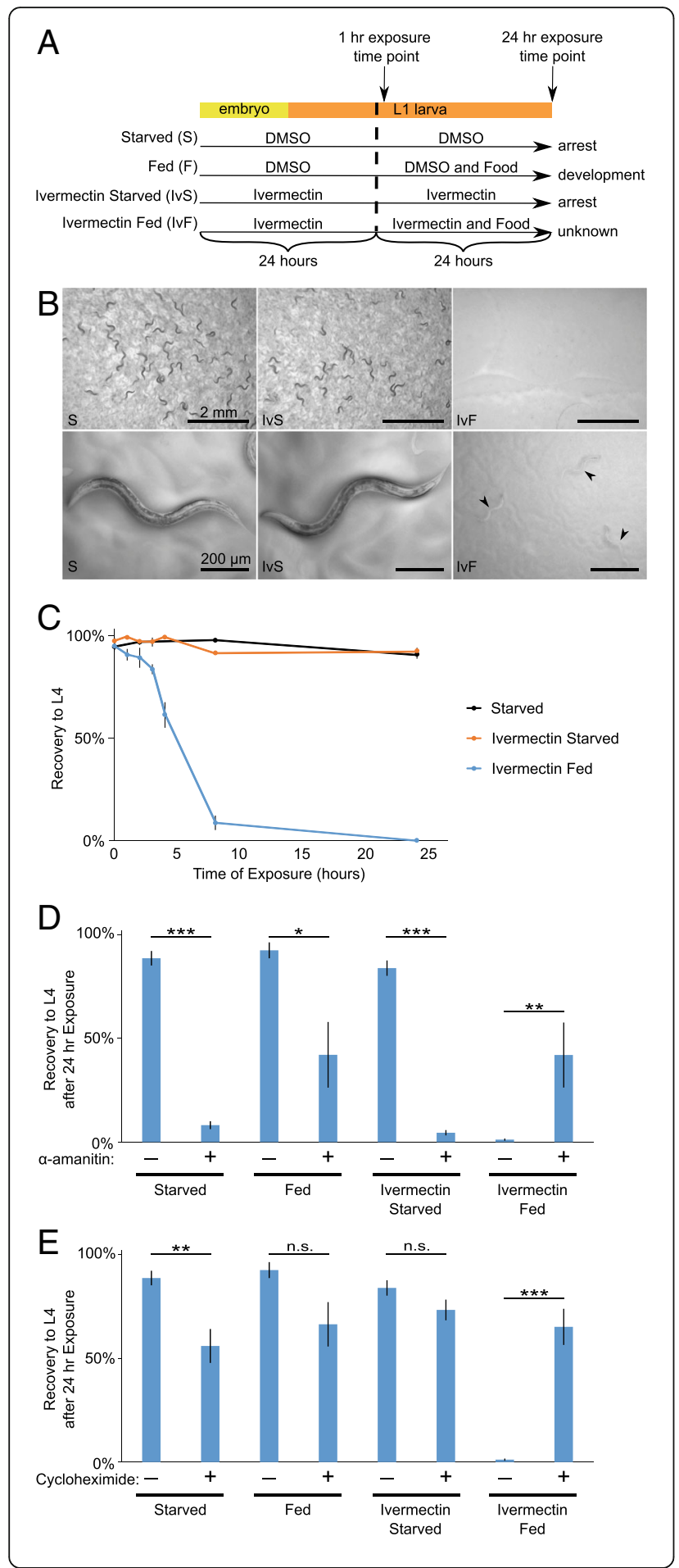

Fig. 1 Prolonged exposure to food perception triggers an inability to recover that is mediated by a transcriptional/translational response. a Diagram of experimental setup with four standard treatment conditions over time. Dimethyl sulfoxide (DMSO; solvent). b Representative images of worm recovery after 3 days post starvation. Arrowheads indicate L1s. C L1 starvation recovery is plotted over time for three biological replicates. d The proportion of larvae that recovered to at least the $L 4$ stage after 3 days of recovery is plotted for three to nine biological replicates. e The proportion of larvae that recovered to at least the $L 4$ stage after 3 days of recovery is plotted for three to nine biological replicates. $\mathbf{b}-\mathbf{e}$ ${ }^{* * *} p<0.001,{ }^{* *} p<0.01 ;{ }^{*} p<0.05$; unpaired $t$ test. Error bars are SEM. Quadruple mutant transgenic background

intermediate growth rates as well. Worms displayed significant failure to recover with as little as $1 \mathrm{mg} / \mathrm{mL}$ HB101 during ivermectin treatment (Additional file 1: Figure S1B), and worms were at least as sensitive to $E$. coli OP50 and HT115 (Additional file 1: Figure S1C). These results indicate that the observed effect of food perception is not limited to a particular strain or high density of $E$. coli. A robust irreversible arrest phenotype following exposure to food in the presence of ivermectin was also observed in wild-type worms (see below; Fig. 3i), indicating that it is not an artifact of the quadruple mutant transgenic strain. Together, these results reveal a potent effect of exposure to $E$. coli without feeding on the ability of $C$. elegans larvae to recover from starvation-induced developmental arrest.

Feeding causes a significant change in transcription and translation in C. elegans L1 larvae $[9,44,60]$. We hypothesized that food perception evokes a gene expression response that is deleterious without feeding, explaining the inability of larvae exposed to food and ivermectin to subsequently resume development. Worms were treated with the drug $\alpha$-amanitin, which inhibits transcription [45, 57, 65], slightly before and during food exposure. Inhibiting transcription significantly increased recovery in worms exposed to ivermectin and food (Fig. 1d). As a complementary approach, worms were treated with cycloheximide to block translation [45] in a similar manner. This treatment also significantly improved recovery in worms exposed to ivermectin and food (Fig. 1e). Notably, inhibition of expression by either method decreased recovery in conditions where perception was consistent with feeding state (i.e., starved, ivermectin starved, and fed), as if gene expression was appropriate in such conditions, supporting fitness. Strikingly, inhibiting expression actually increased recovery in the condition in which perception is inconsistent with feeding state (ivermectin fed), as if gene expression is inappropriate to the starved state, compromising fitness. Together, these results suggest that food perception alters gene expression and that this change in expression affects the animal adversely if it is not accompanied by feeding. 


\section{Food perception evokes a gene expression response similar to feeding}

We performed mRNA-seq to characterize the effects of food perception on gene expression. We assayed quadruple mutant transgenic larvae that were exposed to ivermectin and food for $1 \mathrm{~h}$ or $24 \mathrm{~h}$ to distinguish relatively immediate and long-term effects. We assayed larvae exposed to ivermectin without food at the same time points for reference, as well as larvae that were fed or starved without ivermectin for $1 \mathrm{~h}$ (a 24-h time point was not included since the fed larvae would have developed to the L3 stage). Principal component analysis revealed a large effect of ivermectin, with ivermectin treatment correlating with the first component (Additional file 2: Figure S2). Feeding significantly affected mRNA expression, as expected, and the second and third principal components separated the fed and starved worms (Fig. 2a). Notably, worms exposed to ivermectin and food for $1 \mathrm{~h}$ were different from worms starved with ivermectin, instead showing greater similarity to fed worms. However, by $24 \mathrm{~h}$ of exposure to ivermectin and food, the expression profile was not significantly different from its starved control. Likewise, 1258 genes were differentially expressed at $1 \mathrm{~h}$ comparing ivermectin with food to ivermectin starved, but only 241 genes were differentially expressed in the same comparison at $24 \mathrm{~h}$ (false discovery rate (FDR) $<0.05$ and an absolute $\log _{2}$ fold change of greater than 0.5; Additional file 3: Dataset S1). These results show that perception of food alters gene expression initially but that this effect subsides over time.

We wondered how well correlated the gene expression response to food perception is with feeding. The magnitude of the feeding response was larger, with 5551 differentially expressed genes at $1 \mathrm{~h}$ compared to 1258 genes in the presence of ivermectin. These gene expression changes were very well correlated, with $98.8 \%$ of genes differentially expressed in both conditions changing in the same direction (Fig. 2b). Indeed, the vast majority of genes affected by food with ivermectin were also affected by feeding (Fig. $2 \mathrm{~d}$, hypergeometric $p$ value $=6.8 \mathrm{e}-353$ ) These results indicate that perception of food evokes a similar, though reduced, gene expression response to

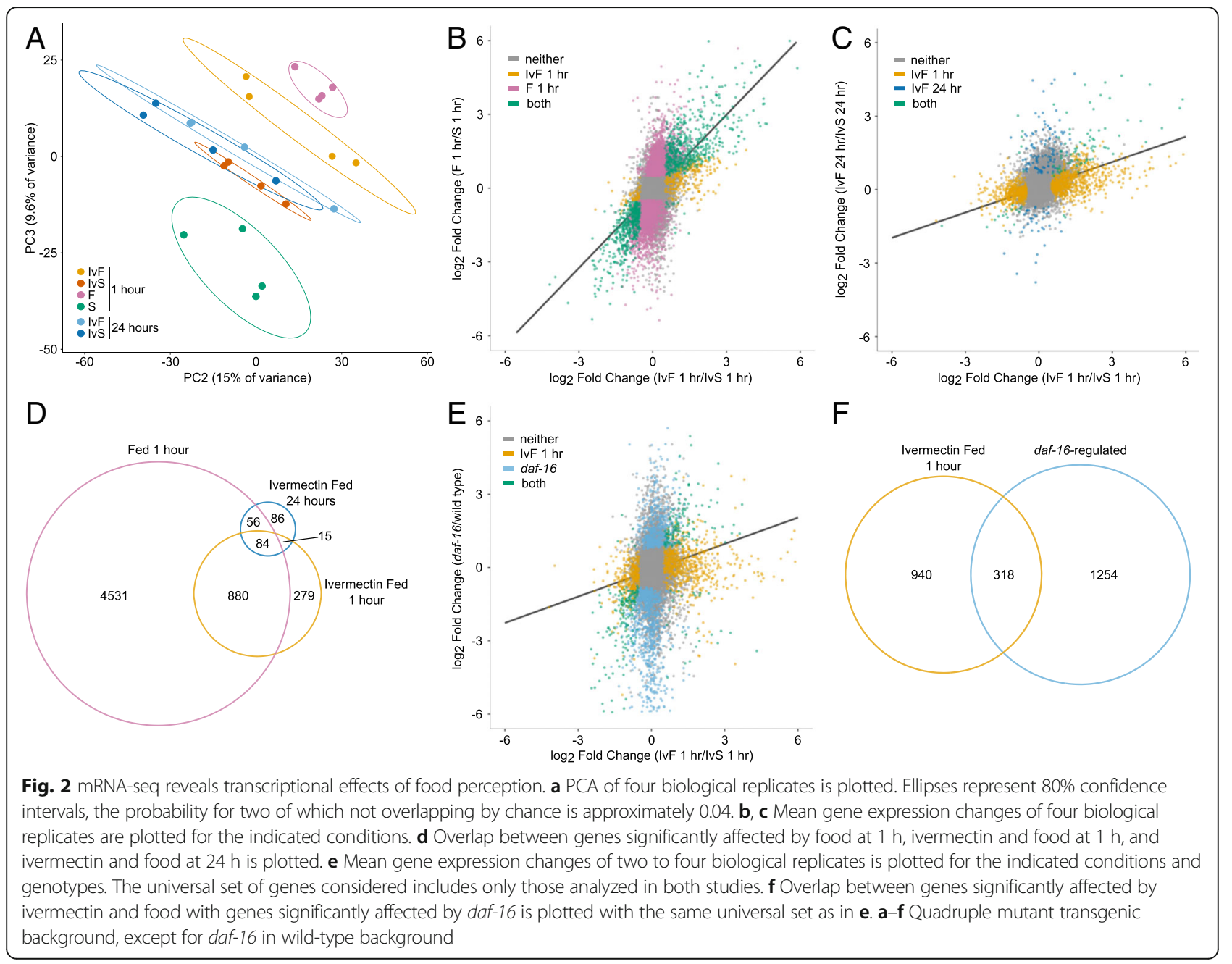


feeding. The response to food in the presence of ivermectin at $1 \mathrm{~h}$ and $24 \mathrm{~h}$ was also well correlated, with 91.9\% of genes differentially expressed at both times responding in the same direction (Fig. 2c). Indeed, there was significant overlap in the differentially expressed genes at both time points (Fig. 2d, hypergeometric $p$ value $=3.7 \mathrm{e}-60)$. These results support the conclusion that perception of food initially alters gene expression in a way that resembles the feeding response but that this response to perception diminishes over time.

As an effector of IIS, daf-16/FOXO is an important regulator of gene expression during L1 starvation $[31,35]$. Since DAF-16 is inactivated by IIS in response to feeding, we hypothesized that it is also inactivated by perception of food, contributing to the resulting gene expression response. We previously identified 1572 genes differentially expressed in a daf-16 null mutant compared to wild-type during L1 starvation [35]. These differences in gene expression correlated with the effect of food in the presence of ivermectin at $1 \mathrm{~h}$, with $88.4 \%$ of the genes significantly affected in both comparisons responding in the same direction (Fig. 2e). There was also significant overlap in the genes affected in both comparisons (Fig. 2f, hypergeometric $p$ value $=2.5 \mathrm{e}-98$ ). These results suggest that perception of food in starved $C$. elegans larvae reduces daf-16/FOXO activity.

\section{Perception of food activates insulin/IGF signaling}

Similarity in the gene expression responses of quadruple mutant transgenic worms exposed to food in the presence of ivermectin (compared to no food with ivermectin) and a starved daf-16/FOXO mutant (compared to starved wild-type worms) suggests that perception of food reduces DAF-16 activity. We further hypothesized that such a decrease in activity is due to activation of IIS. Since IIS regulates subcellular localization of DAF-16 [30, 64], perception of food should affect localization if this hypothesis is correct. We analyzed GFP::DAF-16 localization in a wild-type background, rather than in the quadruple mutant transgenic strain (see "Methods"), because the fluorescent markers in the quadruple mutant transgenic strain would have interfered with observation of GFP::DAF-16. We categorized GFP::DAF-16 localization as nuclear, intermediate, or cytoplasmic (Fig. 3a). As expected [30], GFP::DAF-16 was primarily nuclear during starvation and primarily cytoplasmic after $1 \mathrm{~h}$ exposure to food (Fig. 3b). One hour exposure to food with ivermectin also significantly shifted GFP::DAF-16 to the cytoplasm, supporting our hypothesis that perception of food activates IIS. Also as expected [64], GFP::DAF-16 was relatively less nuclear after $24 \mathrm{~h}$ of starvation than at $1 \mathrm{~h}$. However, after $24 \mathrm{~h}$ exposure to food, there was no difference between ivermectin-fed and ivermectin-starved worms, in contrast to $1 \mathrm{~h}$ exposure to food in the presence of ivermectin. Similar to mRNA-seq results showing a substantially larger effect at $1 \mathrm{~h}$ exposure to food in the presence of ivermectin than at $24 \mathrm{~h}$ (Fig. $2 \mathrm{~b}-\mathrm{d}$ ), this result suggests that perception of food is sufficient to alter DAF-16 localization initially but not to maintain it in the cytoplasm. GFP::DAF-16 localization also responds to other bacterial strains in the presence of ivermectin (Additional file 4: Figure S3A). These results suggest that perception of each of the bacterial strains typically used as food in the lab can activate IIS.

The C. elegans genome encodes 40 insulin-like peptides, and genetic analysis suggests they function as agonists or antagonists of DAF-2/InsR [51]. We wondered if the expression of specific insulin-like peptides was affected by food perception, potentially accounting for activation of IIS. Based on our mRNA-seq results, expression of two insulin-like peptides, ins-12 and ins-24, was significantly downregulated after $1 \mathrm{~h}$ exposure to food in the presence of ivermectin $\left(\log _{2} \mathrm{FC}=-2.3\right.$, $\mathrm{FDR}=0.004$ and $\log _{2} \mathrm{FC}=-0.72, \mathrm{FDR}=0.001$, respectively). Previous characterization revealed complex expression of ins-12 in fed and starved L1 larvae as well as opposite functional effects on dauer entry and exit, precluding classification as a putative agonist or antagonist $[17,24]$. ins-24 expression decreases in response to feeding during recovery from L1 arrest, suggesting it functions as an antagonist, though this conclusion is not supported by functional analysis [17]. Nonetheless, downregulation of ins-12 and ins-24 in response to food perception tentatively suggests these two insulin-like peptides may function as DAF-2 antagonists in this context.

In contrast to putative DAF-2/InsR antagonists, putative agonists have been functionally characterized during $\mathrm{L} 1$ arrest and recovery. The insulin-like peptides daf-28, ins-4, ins -5 and ins- 6 are transcriptionally upregulated by feeding L1 larvae, and daf-28, ins-4 and ins-6 promote L1 development [17], consistent with function as DAF-2/InsR agonists in regulation of dauer development [18, 40,51]. We found that daf-28, ins-5, and ins-6 transcripts were significantly upregulated after $1 \mathrm{~h}$ exposure to food in the presence of ivermectin (Fig. 3c). We used the COPAS BioSorter to quantify whole-worm fluorescence of a Pdaf-28::GFP transcriptional reporter, supporting the conclusion that daf- 28 transcription increases in response to food perception (Fig. 3d). This reporter was expressed in anterior neurons, previously identified as the amphid chemosensory neurons ASIL/R and ASJL/R [40], and the posterior intestine with higher expression after 6 h feeding (Fig. 3e), as expected [17]. Consistent with the COPAS results and mRNA-seq, the reporter was also brighter after exposure to food in the presence of ivermectin. These results reveal transcriptional upregulation of putative DAF-2/InsR agonists including daf-28 as an initial response to perception of food, consistent with activation of IIS. 

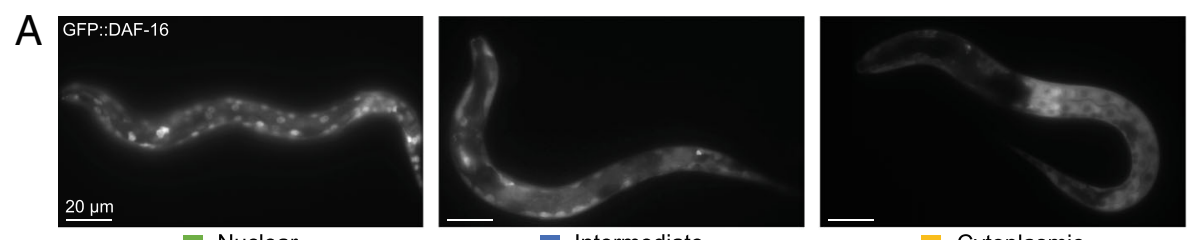

Nuclear

Intermediate

Cytoplasmic
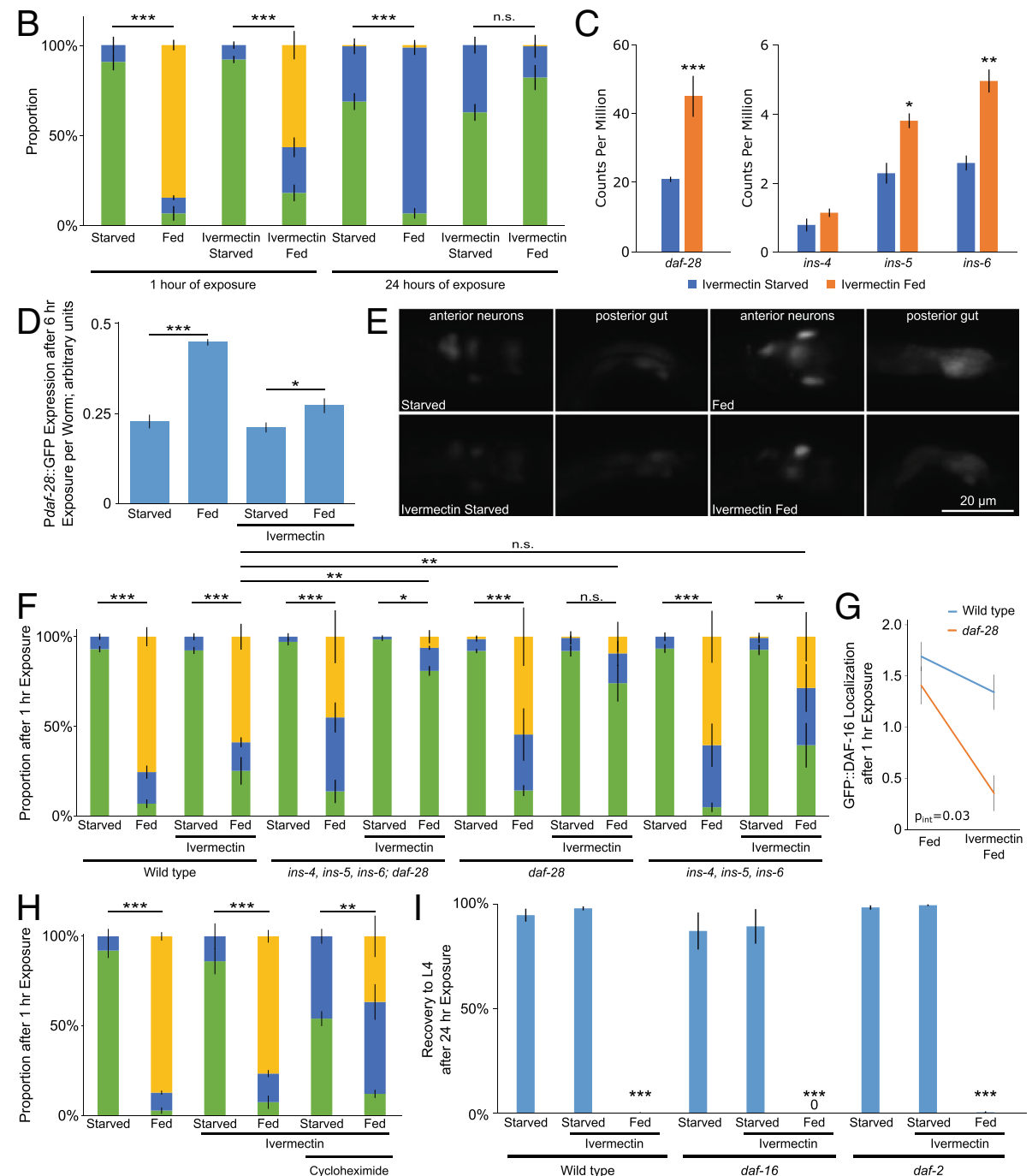

Fig. 3 GFP::DAF-16 localization response to food perception is insulin-dependent. a Representative images of how GFP::DAF-16 localization was characterized. $\mathbf{b}$ GFP::DAF-16 localization is plotted for three biological replicates. c Average transcript abundance from four biological replicates of mRNA-seq is plotted for selected insulin-like peptides. Nominal $p$ values displayed. $\mathbf{d}$ Averages of Pdaf-28:GFP fluorescence intensity normalized by optical extinction per worm using the COPAS BioSorter are plotted for four biological replicates. Exposure to HB101 was 6 h. e Representative images of Pdaf-28:GFP transcriptional reporter gene are presented. f GFP::DAF-16 localization is plotted for three to six biological replicates. $\mathbf{g}$ GFP::DAF-16 localization is plotted for three to six biological replicates. The two-way ANOVA interaction $p$ value is listed. $\mathbf{h}$ GFP::DAF-16 localization is plotted for three biological replicates. $\mathbf{i}$ The proportion of larvae that recovered to at least the $L 4$ stage after 3 days of recovery is plotted for three to four biological replicates. $\mathbf{b}-\mathbf{i}{ }^{* * *} p<0.001,{ }^{* *} p<0.01$; ${ }^{*} p<0.05$; unpaired $t$ test. Error bars are SEM, except for in $\mathbf{d}$ where they are standard deviation. $\mathbf{a}, \mathbf{b}, \mathbf{d}-\mathbf{i}$ Wild-type background. c Quadruple mutant transgenic background

We performed genetic analysis of our candidate DAF-2/InsR agonists to determine functional relevance in activation of IIS in response to food perception. We used null alleles for the insulin genes and assayed GFP::DAF-16 localization in an otherwise wild-type background. As a control, mutation of $d a f-2 /$ InsR completely blocked the effects of food on GFP::DAF-16 localization (Additional file 4: Figure S3B). Functional redundancy among the 40 insulin genes is common [51], particularly in regulation of L1 arrest and recovery, but 
simultaneous disruption of multiple genes can reveal loss-of-function phenotypes [17]. ins- 4,5 and 6 are clustered on chromosome II, and a deletion allele that removes all three causes constitutive dauer formation [34]. Combination of this deletion allele with a daf-28 deletion allele to simultaneously disrupt all four putative agonists reduces L1 starvation survival [17]. This compound mutant retained the response to feeding, with GFP::DAF-16 moving from the nucleus to the cytoplasm (Fig. 3f), revealing robust regulation of DAF-16 localization. However, the change in localization in response to food in the presence of ivermectin was significantly reduced in the compound mutant (Fig. 3f). The daf-28 deletion alone mimicked the behavior of the compound mutant, but the ins-4, 5, 6 deletion alone did not, suggesting $d a f-28$ specifically mediates the response to food perception. To examine this closer, we plotted the data for wild-type and the daf-28 mutant separately, focusing on the effect of food in the presence and absence of ivermectin (Fig. 3g). These data show a specific effect of $d a f-28$ on the response to food in the presence of ivermectin (two-way ANOVA $p$ values for interaction between genotype and presence or absence of ivermectin: daf- $28=0.03$, ins-4, 5, 6; daf-28 $=0.02$, ins $-4,5,6=0.29$ ). These data suggest that $d a f-28$ plays a critical role in mediating the initial response to food perception on IIS activity, and they suggest that overlapping function of insulin-like peptides provides a more robust response to feeding than perception alone.

We reasoned that perception of food likely promotes secretion, in addition to synthesis, of DAF-28 and other putative DAF-2 agonists from chemosensory neurons, providing a rapid response to environmental conditions. To address this hypothesis, we treated worms with cycloheximide to block translation and examined GFP::DAF-16 localization. Even in the presence of cycloheximide, exposure of ivermectin-treated larvae to food caused a cytoplasmic shift in GFP::DAF-16 localization (Fig. 3h). Cycloheximide treatment constitutes a massive perturbation, affecting innumerable processes, but this result is consistent with perception of food affecting insulin-like peptides posttranslationally, possibly at the level of secretion. However, the shift in GFP::DAF-16 localization was incomplete with cycloheximide treatment, suggesting incomplete inhibition of translation and/or additional regulatory mechanisms. Together with our results showing an effect of food perception on daf-28 transcription (Fig. 3c-e), these results suggest that food perception affects insulin-like peptide activity at multiple levels of regulation, in particular transcriptionally and posttranslationally.

Given the effects of food perception on IIS, we hypothesized that IIS mutants affect the irreversible arrest resulting from perception without feeding. If cytoplasmic localization of DAF-16 during starvation were sufficient to cause the irreversible arrest phenotype, then daf-16 mutants should not be able to recover following starvation. Daf-16 mutants are starvation-sensitive, but they nonetheless can be starved and retain the ability to recover upon feeding (Fig. 3i). Testing for necessity of IIS activation in causation of the irreversible arrest phenotype would require blocking IIS during food exposure. Null $d a f-2 /$ InsR mutations are inviable [50], so we can only partially block IIS with a daf-2 partial loss-of-function mutant. The daf-2/InsR mutant did not display increased recovery after exposure to food in the presence of ivermectin (Fig. 3i). Together, these results suggest that fully functional IIS is not necessary nor is altered IIS sufficient to cause the irreversible arrest. It is possible that altered IIS is irrelevant to the irreversible arrest phenotype, but we believe instead that the basis for the phenotype is complex and caused by alteration of multiple pathways such that manipulation of any one pathway alone during starvation will not cause irreversible arrest.

\section{Perception of food is not sufficient to promote development} We used Gene Ontology (GO) term enrichment analysis of our mRNA-seq results to get a broad view of the processes affected by perception of food. The response to feeding for $1 \mathrm{~h}$ revealed significant overlap with metabolism genes (hypergeometric $p$ value $=8.6 \mathrm{e}-92$ ) and larval development genes (Fig. 4a, hypergeometric $p$ value $=9.8 \mathrm{e}-39$ ). The response to food exposure for $1 \mathrm{~h}$ in the presence of ivermectin also revealed significant overlap with metabolism genes (Fig. 4b, hypergeometric $p$ value $=5.0 \mathrm{e}-23$ ) but not with larval development genes (hypergeometric $p$ value $=0.89$ ). Furthermore, genes differentially expressed in response to both food exposure in the presence of ivermectin and feeding were enriched for metabolic GO terms, while genes differentially expressed in response to feeding but not exposure to food in the presence of ivermectin were enriched for a variety of GO terms related to development (Additional file 3: Dataset S1, Additional file 5: Tables S1 and S2). These results suggest that perception of food affects metabolism but not development.

The lateral epidermal seam cells are the first cells to divide in developing L1 larvae [61], and they divide very rarely during L1 arrest [11, 35]. We used an AJM-1::GFP reporter for adherens junctions to visualize seam cell membranes and count divisions of the cells v1-6 [29] Consistent with the results of GO term analysis, exposure to food for 2 days in the presence of ivermectin did not cause seam cell divisions (Fig. 4c). There were also no M-cell divisions (data not shown). These results with the most stringent assay available indicate that perception of food is not sufficient to promote detectable postembryonic development. 


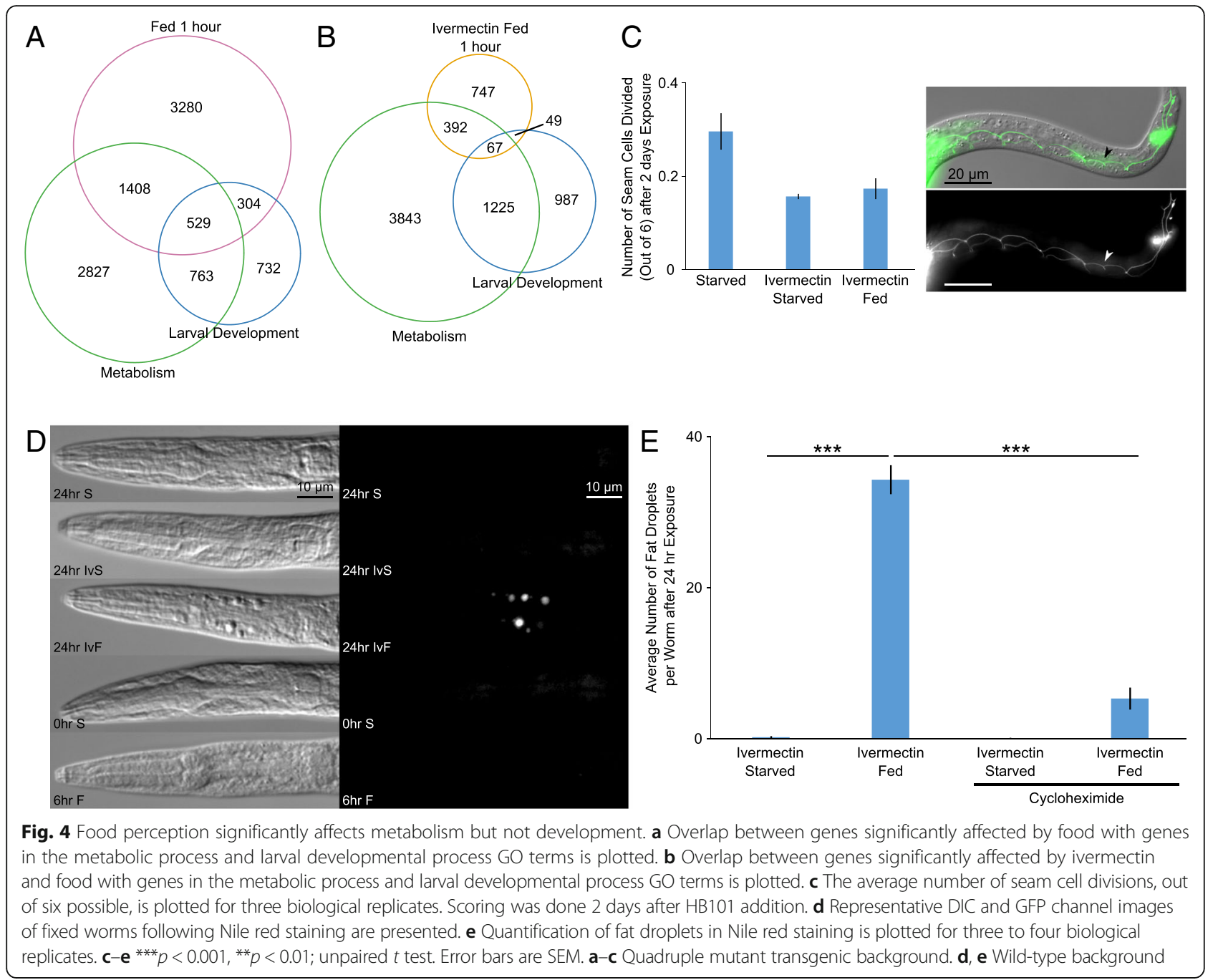

\section{Perception of food alters lipid metabolism}

We were particularly interested in distinct effects of food perception alone compared to feeding, since exposure of larvae to food in the presence of ivermectin caused irreversible developmental arrest. We therefore examined GO term enrichments among genes significantly affected by food exposure in the presence of ivermectin but not by feeding after $1 \mathrm{~h}$ (Table 1). This set of genes was enriched for fatty acid and lipid metabolic GO terms, especially those related to catabolism and oxidation. Examination of individual genes contributing to these GO term enrichments identified genes involved in fatty acid breakdown (e.g., cpt-1,2, acox-1,2, acdh-12, ech-1.1,1.2, and acaa-2) as upregulated after $1 \mathrm{~h}$ of food perception. However, genes involved in fatty acid biogenesis (e.g., fasn-1 and acs-5) were also upregulated, suggesting complex effects on lipid metabolism.

Microscopic analysis of larvae further supports the conclusion from GO term enrichments that lipid metabolism is affected by perception of food. Differential interference contrast microscopy revealed numerous, prominent droplets throughout the body and around the pharynx, as if in the body cavity, after prolonged exposure to food in the presence of ivermectin (Fig. 4d). Given their appearance and GO term enrichments (Table 1), we hypothesized that these are lipid droplets. Nile red staining of fixed L1 larvae confirmed that these droplets contained lipid, supporting our hypothesis (Fig. 4d). Staining was done in a wild-type background, as opposed to a quadruple mutant transgenic background, to avoid interference from fluorescent reporters. Starved L1 larvae, either shortly after hatching or $24 \mathrm{~h}$ later, did not contain such lipid droplets. Fed L1 larvae developed small lipid droplets in the intestine, while the droplets in worms exposed to food and ivermectin for $24 \mathrm{~h}$ were more varied in size and location. Cycloheximide treatment significantly reduced the number of lipid droplets caused by food in the presence of ivermectin (Fig. 4e). This result suggests that the change in lipid metabolism that gives rise to these abnormal lipid droplets is due to 
Table 1 Food perception affects lipid metabolism-related GO terms

\begin{tabular}{llllll}
\hline GO term description & FDR & Enrichment & $\begin{array}{l}\text { Number of genes } \\
\text { in GO term }\end{array}$ & $\begin{array}{l}\text { Number of genes } \\
\text { in target set }\end{array}$ & $\begin{array}{l}\text { Number of genes } \\
\text { in overlap }\end{array}$ \\
\hline Fatty acid beta-oxidation & $8.93 \mathrm{E}-08$ & 16.69 & 36 & 227 & 10 \\
Lipid oxidation & $2.62 \mathrm{E}-07$ & 15.02 & 40 & 227 & 10 \\
Fatty acid oxidation & $2.46 \mathrm{E}-07$ & 15.02 & 40 & 227 & 10 \\
Fatty acid catabolic process & $1.95 \mathrm{E}-08$ & 14.71 & 49 & 227 & 12 \\
Monocarboxylic acid catabolic process & $2.71 \mathrm{E}-08$ & 14.13 & 51 & 227 & 12 \\
Fatty acid metabolic process & $1.97 \mathrm{E}-11$ & 11.30 & 101 & 227 & 19 \\
Cellular lipid catabolic process & $4.34 \mathrm{E}-07$ & 10.30 & 70 & 227 & 12 \\
Carboxylic acid catabolic process & $5.10 \mathrm{E}-08$ & 10.01 & 84 & 227 & 14 \\
Organic acid catabolic process & $5.67 \mathrm{E}-08$ & 10.01 & 84 & 14
\end{tabular}

Top GO terms ranked by enrichment values (at least 10 -fold) are listed for genes significant in IVF vs. IVS at $1 \mathrm{~h}$ but not $\mathrm{F}$ vs. $\mathrm{S}$ at $1 \mathrm{~h}$ from four biological replicates of mRNA-seq. A quadruple mutant transgenic strain was used for mRNA-seq. Full list is available in Additional file 3: Dataset S1

differential gene expression, consistent with our mRNAseq results (Table 1). We conclude that the gene expression response to food perception alters lipid metabolism, resulting in abnormal accumulation of large lipid droplets in the body cavity.

\section{Polypeptides serve as an environmental cue for food}

Nematodes rely on mechanosensory and chemosensory cues to regulate locomotion, development, pathogen avoidance, feeding, and mating $[7,28]$. C. elegans respond to mechanosensory stimulation when encountering a bacterial lawn, which can be mimicked with Sephadex beads [58]. To test whether the effects of food perception were due to mechanosensation or chemosensation, we assayed the ability to recover after starvation in the presence of ivermectin and Sephadex beads or HB101 bacterial filtrate, respectively. We found that Sephadex beads did not affect starvation recovery, while HB101 filtrate prevented recovery as strongly as HB101 itself (Fig. 5a, Additional file 1: Figure S1A). These data suggest that the deleterious effect of food perception without ingestion is via chemosensation and not mechanosensation.

Since the relevant modality of perception appeared to be chemosensory, we wanted to identify a molecular component of bacterial food that functions as an environmental cue for the worm. We found that LB medium, a common nutrient broth for culturing $E$. coli, as well as its components, yeast extract and tryptone, caused irreversible arrest in worms exposed to them in the presence of ivermectin, similar to the effect of HB101 (Fig. 5b). Yeast extract results from autolysis of $S$. cerevisiae and contains a complicated mixture of amino acids, nucleic acids, peptides, carbohydrates, and vitamins. Tryptone is a tryptic digest of the protein casein, resulting in peptides of varying lengths (dipeptides and larger). Since tryptone is much simpler than yeast extract, we decided to focus our investigation there. We tested undigested casein and casamino acids, which is casein that has been through acid

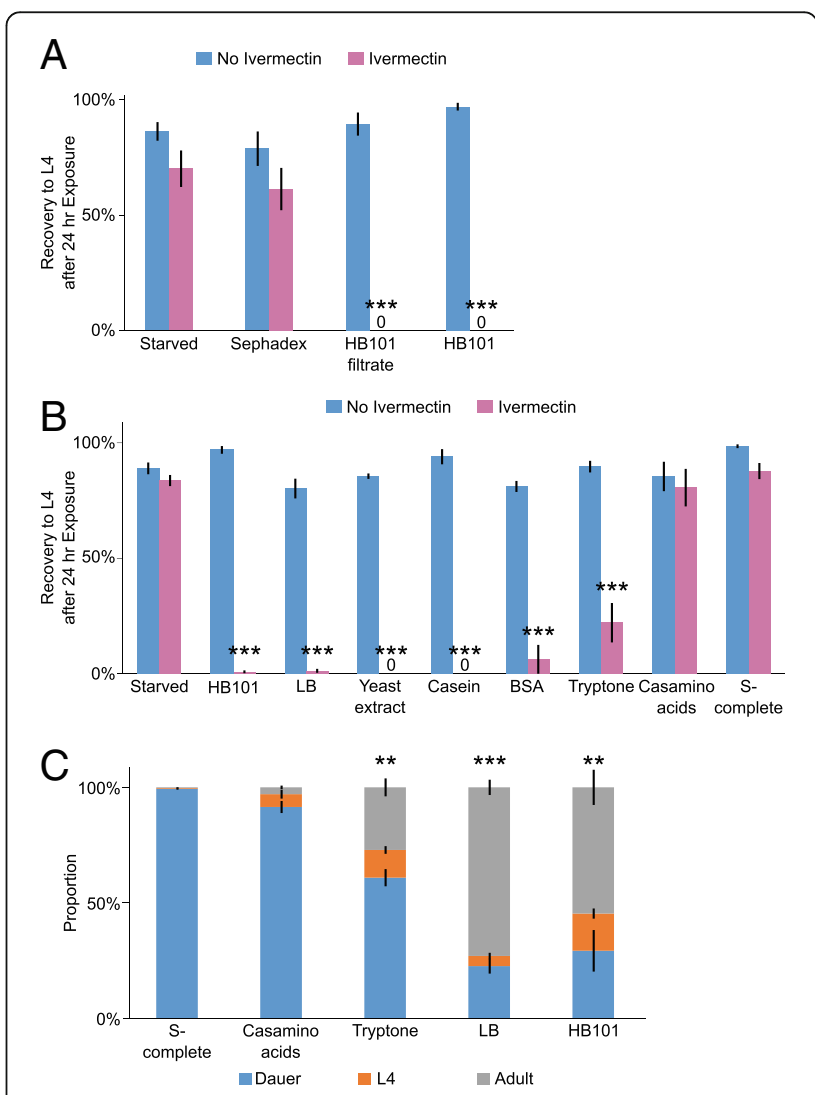

Fig. 5 Perception of food cues affects $L 1$ and dauer recovery. a-b The proportion of larvae that recovered to at least the $L 4$ stage after 3 days of recovery is plotted for three to 13 biological replicates. c Recovery from dauer after 3 days in each condition is plotted for three to four biological replicates. $\mathbf{a}-\mathbf{c}^{* * *} p<0.001,{ }^{* *} p<0.01,{ }^{*} p<0.05$; unpaired $t$ test. Error bars are SEM. a, b Quadruple mutant transgenic background. $\mathbf{c}$ Wild-type background 
hydrolysis to produce free amino acids. We also tested bovine serum albumin (BSA) as another form of protein. We found that exposure to casein or BSA in the presence of ivermectin caused the irreversible arrest phenotype while casamino acids did not (Fig. 5b). Since casamino acids do not contain polypeptide, together these results suggest that polypeptide is perceived. We also exposed ivermectin-treated larvae to a solution of the ten essential amino acids for C. elegans, ethanol, glucose, and a combination of all three and found that none of these significantly affected recovery (Additional file 6: Figure S4A). Perception of polypeptides and other potential food cues also caused GFP::DAF-16 to translocate to the cytoplasm (Additional file 6: Figure S4B, C), consistent with activation of IIS. When otherwise starved larvae were permitted to ingest polypeptide or other potential cues, they supported survival (Additional file 6: Figure S4D) but not development (based on the M-cell division assay; data not shown), as if providing an incomplete source of nutrition. This treatment also compromised the ability of larvae to subsequently recover in standard culture conditions (Additional file 6: Figure S4E, F). This effect is reminiscent of the effect of exposure to food in the presence of ivermectin, consistent with a deleterious effect of perception of food-associated cues without being fed a complete source of nutrition. In summary, we conclude that starved worms perceive polypeptides, presumably as a food-associated cue, though other cues are likely to also be involved.

We wanted an alternative and arguably more ecologically relevant approach than using ivermectin to determine if starved worms perceive polypeptide. Dauer larvae have an internal plug blocking the pharynx and do not pump, preventing them from feeding $[14,54]$. While both L1 arrest and dauer arrest are naturally occurring, dauer larvae are naturally incapable of feeding, but blocking ingestion in L1 larvae has to be experimentally induced (e.g., with ivermectin). Dauer larvae therefore provide a compelling alternative to ivermectin treatment for the analysis of food perception without ingestion. We found that tryptone and LB promoted dauer recovery, as did HB101, while casamino acids and the buffer S-complete did not (Fig. 5c). These results further support the conclusion that C. elegans perceive environmental polypeptides when starved as a food-associated cue.

\section{Discussion}

We sought to uncouple the effects of food perception and ingestion on development, gene expression and metabolism of the nematode C. elegans. We report that perception is not sufficient to promote postembryonic development, but that it activates IIS and alters gene expression and lipid metabolism, resulting in an irreversible arrest phenotype. We also report that starved larvae sense environmental polypeptides, as if worms use them as a food-associated cue to anticipate feeding and development.

The most striking phenotype we report is the irreversible developmental arrest of larvae that are starved in the presence of food, so that they perceive food without eating it. Notably, ivermectin binding has been characterized as irreversible [19, 32, 63]. These studies involved very different time scales from ours, and they used ivermectin doses 50-100-fold greater than us. Nonetheless, we considered irreversible binding as an explanation for irreversible arrest, but several lines of evidence suggest otherwise. Worms exposed to the relatively low dose of ivermectin we used without food almost completely recover. Also, recovery was rescued by blocking transcription or translation during exposure to ivermectin and food. In addition, we see a similar reduction in recovery rate in otherwise starved L1 larvae exposed to food cues. This observation along with the effect of ivermectin and food suggests that perception of food cues without ingestion of complete nutrition underlies the irreversible arrest phenotype. We found that food perception activates IIS, affecting gene expression, but genetic analysis of a daf-16 null mutant suggests that activation of IIS during starvation does not on its own cause an irreversible arrest phenotype (Fig. 3i). Furthermore, irreversible arrest is still triggered by food in ivermectin-treated animals in the absence of a fully functional IIS pathway, as revealed by analysis of daf-2(e1370), a partial-loss-offunction allele. We interpret this as an indication that food perception alters multiple pathways, which may redundantly cause the phenotype, but that modulation of any one of them is not sufficient to cause irreversible arrest. We speculate that perception of food alters metabolism to prime the animal for feeding and development, but that these physiological changes lead to the loss of the stress-resistant properties that normally accompany L1 arrest such that they are detrimental if not accompanied by feeding.

We present evidence that food perception elicits a gene expression response that is largely subsumed by the feeding response and that this response is in part due to activation of IIS. Reduction of IIS and activation of DAF-16/FOXO during L1 starvation affects metabolic gene expression, promoting carbon flux through the glyoxylate shunt, gluconeogenesis, and into the disaccharide trehalose [31]. The gene expression response to feeding for $1 \mathrm{~h}$ tentatively suggests reversal of this starvation response, including apparent downregulation of the glyoxylate shunt (icl-1 expression) and trehalose synthesis (tps-1 and tps-2 expression). Of these gene expression changes, downregulation of the trehalose synthase gene tps-1 alone was also observed in response to food perception for $1 \mathrm{~h}$. While this is consistent with a 
decrease in trehalose synthesis in response to food perception, it is a relatively limited effect on central carbon metabolic gene expression, and we have no additional evidence that carbohydrate metabolism is affected by food perception.

Insulin-like peptides daf-28, ins-6 and ins-4 govern postembryonic development, and their transcription is positively regulated by nutrient availability $[17,18,40]$. We show that daf-28 transcription is upregulated by perception of food and that it plays a specific role in activating IIS in response to perception. That is, daf- 28 was specifically required for food perception to cause GFP::DAF-16 translocation to the cytoplasm, though it was dispensable for translocation in response to feeding, suggesting overlapping function with other insulin-like peptides in the latter but not former case. GFP::DAF-16 translocation to the cytoplasm in response to food perception occurred in the presence of the translational inhibitor cycloheximide, consistent with perception affecting insulin-like peptide activity posttranslationally, possibly at the level of secretion.

The gene expression response and activation of IIS were relatively transient, as if larvae initially respond to food perception but this response is not maintained without feeding and ingestion of nutrients. We imagine that the transient nature of this response is due to habituation of perception or antagonism from internal starvation signals, or a combination of the two. Upregulation of IIS during L1 starvation promotes cell division [17], but perception of food did not, though IIS was activated. We believe the transient nature of IIS activation by food perception explains the lack of postembryonic development. Despite the transient nature of the responses to food perception, they nonetheless have physiological consequences as demonstrated by accumulation of lipid droplets and irreversibility of developmental arrest.

Where the gene expression response to food perception differed from the feeding response, GO term enrichments suggest an effect on lipid metabolism. Food perception specifically increased expression of genes related to both catabolism and synthesis of fatty acids. Expression analysis of adults treated with ivermectin to limit food consumption also suggested an effect on lipid catabolism gene expression [37]. Simultaneous increase of catabolism and synthesis is paradoxical, but we imagine this could reflect interconversion of lipid species and/or result from measuring mRNA expression in whole animals, with metabolism varying among tissues. Nonetheless, perception of food caused accumulation of abnormal, prominent lipid droplets in the body cavity, consistent with an effect on lipid metabolism and storage.

Perception of a "food signal" from bacterial cultures or yeast extract stimulates dauer recovery [27]. $\mathrm{NAD}^{+}$triggers dauer recovery [48], but other components of the "food signal" are not known. We identified polypeptides as a food-associated cue for starved larvae. Perception of polypeptide in the form of casein, BSA, or tryptone in starved L1 larvae caused an irreversible arrest phenotype indistinguishable from that caused by perception of bacteria. Perception of polypeptide also caused GFP::DAF-16 to translocate to the cytoplasm in starved larvae. Furthermore, polypeptide triggered recovery from dauer arrest, a non-feeding state, suggesting polypeptide is a component of the "food signal". Our results suggest a critical role of polypeptide perception in governing postembryonic development of free-living nematodes.

Together our results suggest a model in which chemosensation of environmental polypeptides promotes transcription and possibly secretion of DAF-28 from ASI and ASJ amphid neurons to mediate systemic effects on gene expression and metabolism (Fig. 6). These changes in gene expression and metabolism prime the animal for feeding and development, but they are deleterious in the absence of feeding and cause an irreversible developmental arrest. However, activation of IIS did not account for the entire gene expression response to food perception, nor did it account for the irreversible arrest phenotype. We conclude that food perception affects additional signaling pathways and that these pathways collaborate with IIS to regulate gene expression and metabolism.

\section{Conclusions}

We conclude that $C$. elegans larvae sense environmental food-associated cues such as polypeptides and that this

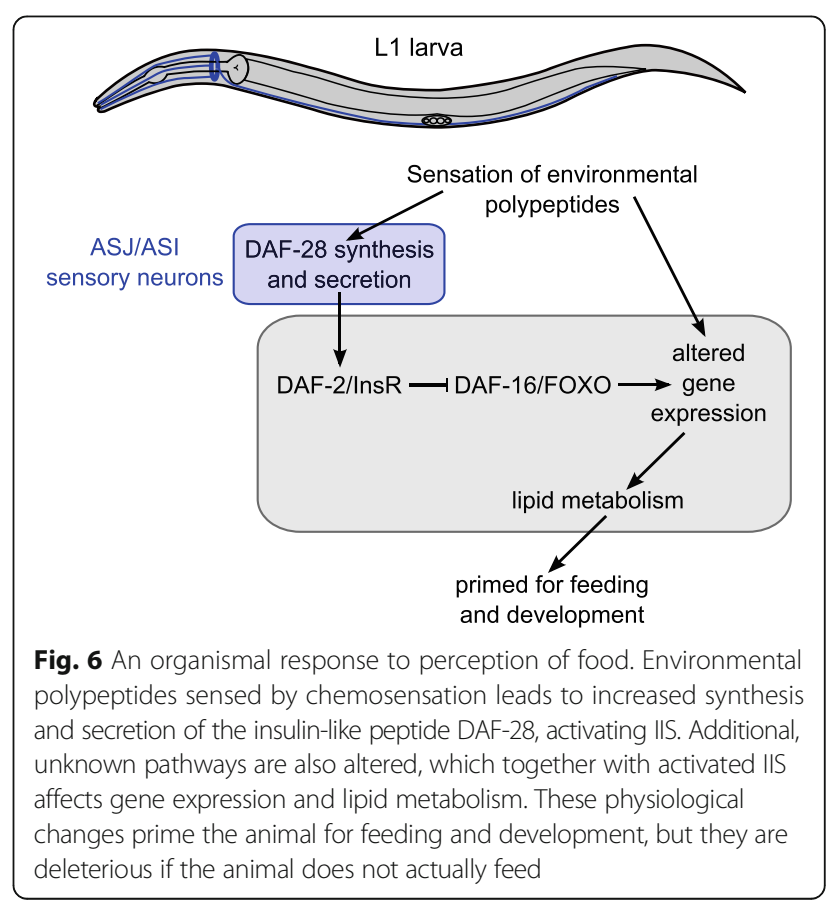


perception affects signaling, gene regulation, and metabolism. We suspect similar physiological effects of food perception, potentially in response to environmental polypeptides, are conserved among nematodes and more broadly among invertebrates. Worms use chemosensation to find food, and food perception may also serve to prime starved larvae for feeding and development. Such priming is apparently detrimental if not accompanied by feeding within hours, but we believe such a scenario where food cues are present without food is unnatural. In contrast, dauer larvae represent a common situation where starved larvae rely on perception to regulate development and metabolism. We show that dauer larvae exit arrest and resume development in response to perception of environmental polypeptides. Starved nondauer larvae are able to feed immediately upon encountering food, but perception of environmental cues could accelerate the organismal response by not requiring ingestion and assimilation of nutrients. With a fluctuating food supply and boom and bust population dynamics in free-living nematodes, we suspect metabolic priming via food perception contributes to fitness by accelerating recovery from developmental arrest.

\section{Methods}

\section{C. elegans strains and ivermectin treatment}

Strains were maintained on agar plates containing standard nematode growth media (NGM) seeded with E. coli OP50 at $20{ }^{\circ} \mathrm{C}$. Small liquid cultures were used to arrest larval development (see below), and E. coli HB101 was used as food in these cultures. Standard genetic techniques were used to make combinations of alleles. The wild-type strain N2 (Bristol) and the following mutant and transgenic strains were used:

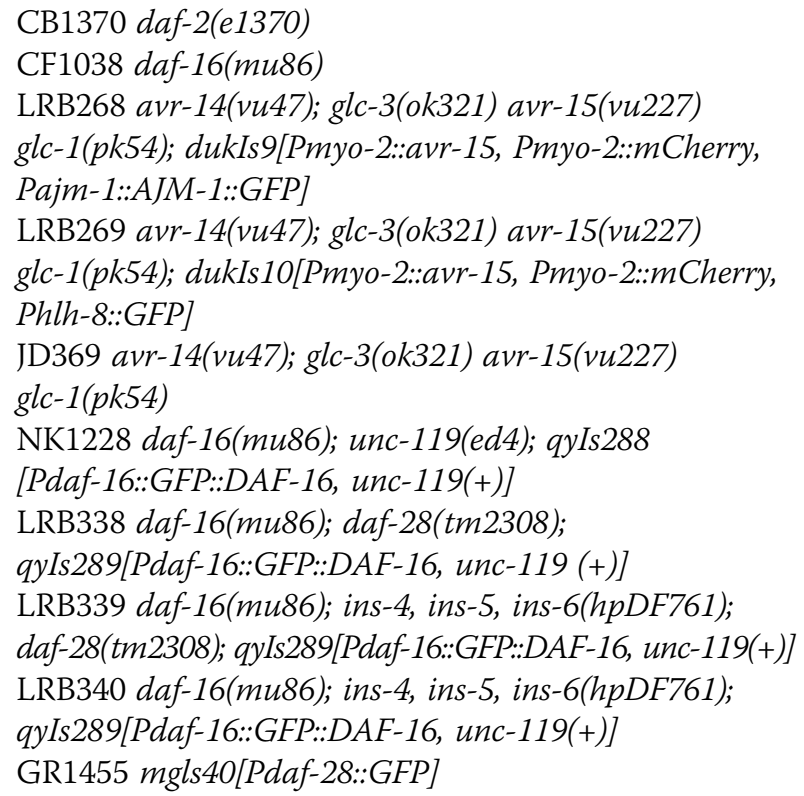

$d u k I s 9$ injection mix contained the following: $1 \mathrm{ng} / \mu \mathrm{L}$ pCFJ90 (Pmyo-2::mCherry), $1 \mathrm{ng} / \mu \mathrm{L}$ pPD30_69_TK414_ 4A (Pmyo-2::avr-15), and $50 \mathrm{ng} / \mu \mathrm{L}$ pJS191 (Pajm-1:: AJM-1::GFP). dukIs10 injection mix contained the following: $1 \mathrm{ng} / \mu \mathrm{L}$ pCFJ90 (Pmyo-2::mCherry), $1 \mathrm{ng} / \mu \mathrm{L}$ pPD30_69_TK414_4A (Pmyo-2::avr-15), and $50 \mathrm{ng} / \mu \mathrm{L}$ pJKL464 (Phlh-8::GFP).

We used LRB268 and LRB269 for our primary analyses. These strains are sensitive to ivermectin in the pharynx alone, providing a controlled way to manipulate pharyngeal pumping. However, these strains have complex genetics, with four chromosomal mutations and a transgenic extrachromosomal array. In addition, the array carries the pharynx-specific avr-15 transgene as well as a reporter gene. Consequently, these two strains were not amenable to analysis of other mutations and reporter genes. We determined that wild-type (N2) worms display similar responses to ivermectin and food (e.g., Fig. 3i), albeit at slightly different doses (see below). We proceeded to use the wild-type background for subsequent genetic analyses. The strain used is indicated for each figure or figure panel.

Ivermectin (Sigma) dissolved in DMSO was added to the appropriate cultures immediately following culture setup. Ivermectin dose was adjusted for different levels of resistance in different strains. We performed a dose response to ivermectin in each background and used the minimal effective dose that made each strain not eat, as assessed by growth (data not shown). LRB269 was treated with $20 \mathrm{ng} / \mathrm{mL}$ ivermectin, or $22.85 \mathrm{nM}$. LRB268 was treated with $50 \mathrm{ng} / \mathrm{mL}$ ivermectin. Strains in the N2 background, rather than the quadruple mutant background, were treated with $10 \mathrm{ng} / \mathrm{mL}$. DMSO was added in equal amounts to control tubes. DMSO concentration ranged from 0.05 to $0.2 \%$.

\section{Hypochlorite treatment and L1 arrest assays}

Mixed-stage cultures of worms on 10-cm NGM plates were washed from the plates using virgin S-basal (S-basal lacking ethanol and cholesterol) and centrifuged for $1 \mathrm{~min}$ at $3000 \mathrm{rpm}$ in $15-\mathrm{mL}$ conical tubes. A hypochlorite solution (7:2:1 $\mathrm{dd}_{2} \mathrm{O}$, sodium hypochlorite (Sigma), $5 \mathrm{M} \mathrm{KOH}$ ) was added to dissolve the animals. Worms were centrifuged after 1.5-2 $\mathrm{min}$ in the hypochlorite solution, and fresh solution was added. Total time in the hypochlorite solution was 7-10 min. Embryos were washed three times in virgin S-basal buffer (no ethanol or cholesterol) before final suspension in 3-6 $\mathrm{mL}$ virgin S-basal at a density of 1 worm $/ \mu \mathrm{L}$. Embryos were cultured in a $16-\mathrm{mm}$ glass tube on a tissue culture roller drum at approximately $25 \mathrm{rpm}$ and $21-22{ }^{\circ} \mathrm{C}$.

For the M-cell division assay, 1 day following the hypochlorite treatment above, the worms were put in the appropriate condition (LB, tryptone, etc.) and cultured for 
7 days before 100 larvae per replicate were examined on a Noble agar slide on a compound fluorescent microscope. For the seam cell division assay, 1 day following the hypochlorite treatment above, HB101 was added at $25 \mathrm{mg} / \mathrm{mL}$ for 2 days and the V1-6 cells on one side of the animal were scored for 60 larvae per replicate.

\section{Starvation recovery}

Animals were treated in hypochlorite solution and suspended in virgin S-basal with DMSO or ivermectin as described above. Twenty-four hours after hypochlorite treatment, the appropriate bacteria (HB101 unless otherwise stated) or potential food cue was added at the appropriate dose $(25 \mathrm{mg} / \mathrm{mL}$ for bacteria unless otherwise stated). HB101 filtrate was created by filtering HB101 at $25 \mathrm{mg} / \mathrm{mL}$ through a $22-\mu \mathrm{m}$ filter. Yeast extract was at $5 \mathrm{mg} / \mathrm{mL}$. Tryptone and casamino acids were at $10 \mathrm{mg} /$ $\mathrm{mL}$. Due to solubility limitations, casein and BSA were at $1 \mathrm{mg} / \mathrm{mL}$. Ethanol was at $0.095 \%(v / v)$. Glucose was at $5 \%(w / v)$ or $278 \mathrm{mM}$. Amino acid solution $(16 \mathrm{mg} / \mathrm{mL})$ was prepared as in [25]. Addition of bacteria or potential food cues was considered the $0 \mathrm{~h}$ exposure time point (vertical dashed line in Fig. 1a). One hundred-microliter aliquots were sampled at the stated times up to $24 \mathrm{~h}$ and placed around the edge of a HB101 lawn on NGM plates. Number of plated worms $\left(T_{\mathrm{p}}\right)$ was counted and the plates were incubated at $20{ }^{\circ} \mathrm{C}$. After 3 days, the number of animals that recovered to at least the L4 stage $\left(T_{\mathrm{R}}\right)$ was counted. Recovery was calculated as $T_{\mathrm{R}} / T_{\mathrm{p}}$.

\section{Fluorescent bead ingestion}

Cultures were setup as for a starvation recovery experiment as above; except instead of plating the worms after $24 \mathrm{~h}$, fluorescent beads (Fluoresbrite ${ }^{\circ}$ YG Carboxylate Microspheres $0.10 \mu \mathrm{m}$ from Polysciences) were added at 1:200 to the cultures. After 3-4 h, the cultures were examined on a Noble agar slide on a compound fluorescent microscope. The location of the fluorescent beads (i.e., gut, pharynx, or none inside the worm) was scored for 40 worms per replicate.

\section{a-Amanitin and cycloheximide treatment}

Dose response curves with $\alpha$-amanitin (Sigma) and cycloheximide (Sigma) were done using the gpIs1 [Phsp-16.2::GFP] reporter [43] in a wild-type background to find a dose that prevented fluorescence in response to heat shock at $33{ }^{\circ} \mathrm{C}$ for $2 \mathrm{~h}$ (data not shown). These doses were determined to be $5 \mathrm{mM}$ for cycloheximide and $25 \mu \mathrm{g} / \mathrm{mL}$ for $\alpha$-amanitin. Both drug stocks were dissolved in water. The starvation recovery assay (Fig. 1d, e) was set up as above in the quadruple transgenic mutant, with drugs added $2 \mathrm{~h}$ before food addition and cultures washed three times with $10 \mathrm{~mL}$ virgin S-basal before plating.

\section{mRNA-seq and associated analysis}

Worm cultures for LRB269 were set up using the hypochlorite treatment as described above, except in S-complete rather than virgin S-basal and scaled up to $20 \mathrm{~mL}$ per condition. Either ivermectin was added at $5 \mathrm{ng} / \mathrm{mL}$ or DMSO was added at $0.1 \%$. Twenty-four hours after hypochlorite treatment, allowing for hatching and synchronization, HB101 was added at $25 \mathrm{mg} / \mathrm{mL}$ to the food tubes. Samples were collected at $1 \mathrm{~h}$ and $24 \mathrm{~h}$ after food addition. To collect the samples, worms were washed three times with $10 \mathrm{~mL}$ virgin $\mathrm{S}$-basal then concentrated in $100 \mu \mathrm{L}$ and frozen in liquid nitrogen. RNA was extracted with Trizol and chloroform. Libraries were prepared for sequencing using the NEBNext Ultra RNA Library Prep Kit for Illumina (E7530) with 250-400 ng of starting RNA per library and 13 cycles of PCR. Libraries were sequenced using Illumina HiSeq 4000. Bowtie was used to map reads to the WS210 genome [38]. Transcripts annotated in WS220 that were mapped to the WS210 genome coordinates were also included, as described previously [44]. Mapping efficiencies ranged from 78 to $85 \%$ for all libraries. HTSeq was used to generate count tables for each library [2]. Count tables were analyzed for differential expression using the edge $R$ package in R [56]. Detected genes were considered those expressed at a level of at least 1 count-per-million (CPM) in at least four libraries, reducing the number of genes included in the analysis to 18,190 . The "calcNormFactors" function was used to normalize for RNA composition, and the tagwise dispersion estimate was used for differential expression analysis. The exact test was used for pairwise comparisons of conditions. Differentially expressed genes were considered those with an FDR $<0.05$ and with $\mid \log _{2}$ (fold change) $\mid>0.5$. Principal component analysis was performed using all libraries and all genes used in differential expression analysis (18,190 genes). Counts-per-million (CPM) values for each gene were mean-normalized across all libraries and $\log 2$ transformed prior to using the prcomp function in R. GO term analysis was performed using GOrilla [22, 23]. AmiGO 2 was accessed to download the genes in the metabolic process GO term (GO:0044710) and the larval development $\mathrm{GO}$ term (GO:0002164) [4, 13, 62]. GEO accession number for the dataset is GSE114955.

\section{GFP::DAF-16 localization}

The qyIs288 [Pdaf-16::GFP::DAF-16, unc-119(+)] and qyIs289 [Pdaf-16::GFP::DAF-16, unc-119(+)] reporters [35] were analyzed in a daf-16(mu86); unc-119(ed4) mutant background. Standard genetic methods were used to cross daf-28(tm2308) and ins-4, 5, 6(hpDf761) into this background as well. Cultures were set up using the hypochlorite treatment as described above. One day later, HB101 was added at $25 \mathrm{mg} / \mathrm{mL}$. One hour or $24 \mathrm{~h}$ 
after food addition, 50 larvae per replicate were examined on a Noble agar slide on a compound fluorescent microscope. For blocking translation, the assay was performed as described, except $5 \mathrm{mM}$ cycloheximide was added $2 \mathrm{~h}$ before food addition.

\section{Reporter gene analysis}

The mgIs40 [Pdaf-28::GFP] reporter [40] was analyzed in a wild-type genetic background. Strain was maintained on NGM agar plates with E. coli OP50 as food at $20^{\circ} \mathrm{C}$. Eggs were prepared by standard hypochlorite treatment as described above. These eggs were used to set up a liquid culture consisting of virgin S-basal with a defined density of 1 worm $/ \mu \mathrm{L}$. Ivermectin was added at $10 \mathrm{ng} / \mathrm{mL}$ to the appropriate cultures. After $18 \mathrm{~h}$ to allow for hatching, the E. coli $\mathrm{HB} 101$ was added at $25 \mathrm{mg} / \mathrm{mL}$ to the fed samples. Six hours post food addition, the samples were washed three times with $10 \mathrm{~mL} \mathrm{~S}$-basal and then run through the COPAS BioSorter measuring GFP fluorescence. Analysis of the COPAS data was performed in R. Data points were removed if they were determined to be debris by size. Fluorescence signal was normalized by optical extinction. For imaging, the samples were prepared in the same way then paralyzed with $3.75 \mathrm{mM}$ sodium azide and placed on a Noble agar slide. Images were taken on a compound fluorescent microscope.

\section{Fixation and Nile red staining}

Cultures of N2 wild-type were set up as for a starvation recovery experiment as above; except instead of plating the worms after $24 \mathrm{~h}$, the cultures were washed three times with $10 \mathrm{~mL}$ virgin S-basal. Worms were concentrated in approximately $100 \mu \mathrm{L}$ and frozen at $-80{ }^{\circ} \mathrm{C}$. Fixation and staining protocol was modified from [52], using 1.7-mL Eppendorf tubes instead of 96-well plates and $200 \mu \mathrm{L}$ solution additions instead of $150 \mu \mathrm{L}$. Images were taken on a compound fluorescent microscope. Fat droplets were quantified using the Analyze Particles function in ImageJ. Images were thresholded using negative controls to remove background. Minimum particle size was set as $1.3 \mathrm{~mm}^{2}$.

\section{Starvation survival}

N2 wild-type animals were treated in hypochlorite solution and suspended in virgin S-basal or the appropriate media as described above. One hundred-microliter aliquots were sampled on different days and placed around the edge of an OP50 lawn on NGM plates. Number of plated worms $\left(T_{\mathrm{p}}\right)$ was counted, and the plates were incubated at $20{ }^{\circ} \mathrm{C}$. After 2 days, the number of animals that survived $\left(T_{\mathrm{s}}\right)$ was counted. Survival was calculated as $T_{\mathrm{s}} / T_{\mathrm{p}}$. Survival curves were obtained by fitting survival data for each trial with the function

$$
S=100-\frac{100}{1+e^{\left(t_{\text {half }}-t\right) / \text { rate }}}
$$

\section{Quantitative image analysis of size}

N2 worms were treated in hypochlorite solution and suspended in virgin $\mathrm{S}$-basal or the appropriate media as described above. At the 50\% survival times determined from starvation survival experiments, the worms were spun down at $3000 \mathrm{rpm}$ for $1 \mathrm{~min}$ and pellets were transferred to OP50 seeded 10-cm NGM plates. Worms were allowed to recover for $48 \mathrm{~h}$ at $20^{\circ} \mathrm{C}$. Worms were then imaged and images were processed using the WormSizer plug-in for Fiji/ImageJ as described [46].

\section{Dauer recovery}

N2 worms were treated in hypochlorite solution as described above then resuspended in S-complete at a density of 5 worms $/ \mu \mathrm{L}$ and $1 \mathrm{mg} / \mathrm{mL} \mathrm{HB} 101$ in $25-\mathrm{mL}$ Erlenmeyer flasks [10]. Flasks were placed on a shaker at $20{ }^{\circ} \mathrm{C}$ for 7 days to form dauers. Cultures were spun down at $3000 \mathrm{rpm}$ for $1 \mathrm{~min}$. Supernatant was aspirated, and the appropriate media (LB, tryptone, etc.) was added, retaining a density of 5 worms $/ \mu \mathrm{L}$. Cultures were returned to shaker for 3 days. Approximately 75-100 worms were placed on a depression slide and scored as dauer, L4, or adult for each measurement.

\section{Data analysis and statistics}

Data were handled in R and Excel. Graphs were plotted in the R packages ggplot2 or Vennerable or Excel. Statistical tests were performed in R or Excel. Starvation survival analysis was performed on $50 \%$ survival times $\left(t_{\text {half }}\right)$, which were obtained as in [35], with unpaired $t$ tests performed where $n$ is the number of replicates.

\section{Additional files}

Additional file 1: Figure S1. Further characterization of ivermectin system and starvation recovery. (A) The proportion of larvae that displayed the stated localization of fluorescent beads three to four hours after bead addition is plotted for three biological replicates. (B-C) The proportion of larvae that recovered to at least the $L 4$ stage after 3 days of recovery is plotted for three to four biological replicates. Ivermectin Resistant $=$ JD369. Ivermectin Sensitive $=$ LRB269. ${ }^{* * *} p<0.001,{ }^{*} p<0.05$; unpaired $t$ test. (A-C) Error bars are SEM. Quadruple mutant transgenic background. (PDF $32 \mathrm{~kb}$ )

Additional file 2: Figure S2. Ivermectin affects transcription in larvae. PCA of four biological replicates is plotted. Ellipses represent $80 \%$ confidence interval. Quadruple mutant transgenic background. (PDF 31 kb)

Additional file 3: Dataset S1. mRNA-seq analysis of food perception. Results of mRNA-seq analysis, including counts per gene, logFC, FDR, GOrilla analysis, and GO term gene lists used are included. (XLSX 18186 kb)

Additional file 4: Figure S3. GFP::DAF-16 localization responds to perception of many bacterial foods and requires daf-2. (A-B) GFP::DAF-16 localization is plotted for three to four biological replicates. ${ }^{* *} p<0.001$; unpaired $t$ test. Error bars are SEM. Wild-type background. (PDF 50 kb) 
Additional file 5: Table S1. Feeding and food perception affect metabolism-related GO terms. Top fifteen GO terms ranked by FDR are listed for genes significant in IVF vs. IVS at $1 \mathrm{~h}$ and $\mathrm{F}$ vs. $\mathrm{S}$ at $1 \mathrm{~h}$ from four biological replicates of mRNA-seq. A quadruple mutant transgenic strain was used for mRNA-seq. Full list available in Additional file 3: Dataset S1. Table S2. Feeding but not food perception affects development-related $\mathrm{GO}$ terms. Top fifteen GO terms ranked by FDR are listed for genes significant in F vs. S at $1 \mathrm{~h}$ but not IVF vs. IVS at $1 \mathrm{~h}$ from four biological replicates of mRNA-seq. A quadruple mutant transgenic strain was used for mRNA-seq. Full list available in Additional file 3: Dataset S1. (DOCX 23 kb)

Additional file 6: Figure S4. Perception and physiological effects of potential food cues. (A) The proportion of larvae that recovered to at least the $L 4$ stage after 3 days of recovery is plotted for three biological replicates. (B-C) GFP::DAF-16 localization is plotted for three to six biological replicates. (D) L1 starvation survival is plotted over time. A logistic regression of mean survival from three biological replicates is shown. (E) Worm length following $48 \mathrm{~h}$ of recovery is plotted relative to $\mathrm{L} 1$ starvation survival. (F) Worm length following $48 \mathrm{~h}$ of recovery is plotted as a density plot, showing altered population composition. (A-E) ${ }^{* * *} p<0.001$, ${ }^{* *} p<0.01$ ${ }^{*} p<0.05$; unpaired $t$ test. Error bars are SEM, except for in $E$ where they are standard deviation. (A) Quadruple mutant transgenic background. (B-F) Wild-type background. (PDF $93 \mathrm{~kb}$ )

\section{Acknowledgements}

We would like to thank Joel Meyer and David R. Sherwood for sharing lab equipment and Baugh lab members for helpful discussions. We thank the Duke University School of Medicine and the Center for Genomic and Computational Biology for use of the Sequencing and Genomic Technologies core resource, which provided RNA sequencing service. Some strains were provided by the CGC, which is funded by NIH Office of Research Infrastructure Programs (P40 OD010440)

\section{Funding}

Funding was provided by the National Institutes of Health (R01GM117408, LRB).

\section{Availability of data and materials}

All data generated or analyzed during this study are included in this published article and its supplementary information files. Additionally, the mRNA-seq datasets generated during the current study are available in the Gene Expression Omnibus (GEO) repository. GEO accession number for the dataset is GSE114955.

\section{Authors' contributions}

REWK and JAD contributed the reagents. REWK, JAD, and LRB conceived and designed the experiments. REWK and RC performed the experiments. REWK and AKW analyzed the data. REWK and LRB wrote the paper. All authors read and approved the final manuscript.

\section{Ethics approval and consent to participate}

Not applicable.

\section{Competing interests}

The authors declare that they have no competing interests.

\section{Publisher's Note}

Springer Nature remains neutral with regard to jurisdictional claims in published maps and institutional affiliations.

\section{Author details}

'Department of Biology, Duke University, Box 90338, Durham, NC 27708-0338, USA. 2Department of Biology, McGill University, Montreal, QC H3A 1B1, Canada.

Received: 13 July 2018 Accepted: 24 September 2018 Published online: 08 October 2018

\section{References}

1. Alcedo J, Kenyon C. Regulation of C. elegans longevity by specific gustatory and olfactory neurons. Neuron. 2004;41(1):45-55.

2. Anders S, Pyl PT, Huber W. HTSeq--a Python framework to work with highthroughput sequencing data. Bioinformatics. 2015;31(2):166-9.
3. Apfeld J, Kenyon C. Regulation of lifespan by sensory perception in Caenorhabditis elegans. Nature. 1999:402(6763):804-9.

4. Ashburner M, Ball CA, Blake JA, Botstein D, Butler H, Cherry JM, Davis AP, Dolinski K, Dwight SS, Eppig JT, Harris MA, Hill DP, Issel-Tarver L, Kasarskis A, Lewis S, Matese JC, Richardson JE, Ringwald M, Rubin GM, Sherlock G. Gene ontology: tool for the unification of biology. The gene ontology consortium. Nat Genet. 2000;25(1):25-9.

5. Avery L, Horvitz HR. Effects of starvation and neuroactive drugs on feeding in Caenorhabditis elegans. J Exp Zool. 1990;253(3):263-70.

6. Avery L, You YJ. C. elegans feeding. In: WormBook; 2012. p. 1-23.

7. Bargmann Cl. Chemosensation in C. elegans. In: WormBook; 2006. p. 1-29.

8. Baugh LR. To grow or not to grow: nutritional control of development during Caenorhabditis elegans L1 arrest. Genetics. 2013;194(3):539-55.

9. Baugh LR, Demodena J, Sternberg PW. RNA pol II accumulates at promoters of growth genes during developmental arrest. Science. 2009;324(5923):92-4.

10. Baugh LR, Kurhanewicz N, Sternberg PW. Sensitive and precise quantification of insulin-like mRNA expression in Caenorhabditis elegans. PLoS One. 2011;6(3):e18086.

11. Baugh LR, Sternberg PW. DAF-16/FOXO regulates transcription of cki-1/Cip/Kip and repression of lin-4 during C. elegans L1 arrest. Curr Biol. 2006;16(8):780-5.

12. Brogiolo W, Stocker H, Ikeya T, Rintelen F, Fernandez R, Hafen E. An evolutionarily conserved function of the Drosophila insulin receptor and insulin-like peptides in growth control. Curr Biol. 2001;11(4):213-21.

13. Carbon S, Ireland A, Mungall CJ, Shu S, Marshall B, Lewis S, Ami GOH, Web Presence Working G. AmiGO: online access to ontology and annotation data. Bioinformatics. 2009;25(2):288-9.

14. Cassada RC, Russell RL. The dauerlarva, a post-embryonic developmental variant of the nematode Caenorhabditis elegans. Dev Biol. 1975;46(2):326-42.

15. Chell JM, Brand AH. Nutrition-responsive glia control exit of neural stem cells from quiescence. Cell. 2010;143(7):1161-73.

16. Chen C, Jack J, Garofalo RS. The Drosophila insulin receptor is required for normal growth. Endocrinology. 1996;137(3):846-56.

17. Chen $Y$, Baugh LR. Ins-4 and daf-28 function redundantly to regulate $C$. elegans L1 arrest. Dev Biol. 2014;394(2):314-26.

18. Cornils A, Gloeck M, Chen Z, Zhang Y, Alcedo J. Specific insulin-like peptides encode sensory information to regulate distinct developmental processes. Development. 2011;138(6):1183-93.

19. Cully DF, Vassilatis DK, Liu KK, Paress PS, Van der Ploeg LH, Schaeffer JM, Arena JP. Cloning of an avermectin-sensitive glutamate-gated chloride channel from Caenorhabditis elegans. Nature. 1994;371(6499):707-11.

20. Dent JA, Davis MW, Avery L. avr-15 encodes a chloride channel subunit that mediates inhibitory glutamatergic neurotransmission and ivermectin sensitivity in Caenorhabditis elegans. EMBO J. 1997;16(19):5867-79.

21. Dent JA, Smith MM, Vassilatis DK, Avery L. The genetics of ivermectin resistance in Caenorhabditis elegans. Proc Natl Acad Sci U S A. 2000;97(6):2674-9.

22. Eden $E$, Lipson D, Yogev S, Yakhini Z. Discovering motifs in ranked lists of DNA sequences. PLoS Comput Biol. 2007;3(3):e39.

23. Eden E, Navon R, Steinfeld I, Lipson D, Yakhini Z. GOrilla: a tool for discovery and visualization of enriched $\mathrm{GO}$ terms in ranked gene lists. BMC Bioinformatics. 2009;10:48.

24. Fernandes de Abreu DA, Caballero A, Fardel P, Stroustrup N, Chen Z, Lee K, Keyes WD, Nash ZM, Lopez-Moyado IF, Vaggi F, Cornils A, Regenass M, Neagu A, Ostojic I, Liu C, Cho Y, Sifoglu D, Shen Y, Fontana W, Lu H, CsikaszNagy A, Murphy CT, Antebi A, Blanc E, Apfeld J, Zhang Y, Alcedo J, Ch'ng Q. An insulin-to-insulin regulatory network orchestrates phenotypic specificity in development and physiology. PLoS Genet. 2014;10(3):e1004225.

25. Fukuyama M, Kontani K, Katada T, Rougvie AE. The C. elegans Hypodermis Couples Progenitor Cell Quiescence to the Dietary State. Curr Biol. 2015;25: 1241-248.

26. Fukuyama M, Rougvie AE, Rothman JH. C. elegans DAF-18/PTEN mediates nutrient-dependent arrest of cell cycle and growth in the germline. Curr Biol. 2006;16(8):773-9.

27. Golden JW, Riddle DL. A pheromone influences larval development in the nematode Caenorhabditis elegans. Science. 1982;218(4572):578-80.

28. Goodman MB. Mechanosensation. In: WormBook; 2006. p. 1-14.

29. Gupta BP, Wang M, Sternberg PW. The C. elegans LIM homeobox gene lin11 specifies multiple cell fates during vulval development. Development. 2003:130(12):2589-601.

30. Henderson ST, Johnson TE. daf-16 integrates developmental and environmental inputs to mediate aging in the nematode Caenorhabditis elegans. Curr Biol. 2001;11(24):1975-80. 
31. Hibshman JD, Doan AE, Moore BT, Kaplan RE, Hung A, Webster AK, Bhatt DP, Chitrakar R, Hirschey MD, Baugh LR. daf-16/FoxO promotes gluconeogenesis and trehalose synthesis during starvation to support survival. Elife. 2017:6:e30057.

32. Horoszok L, Raymond V, Sattelle DB, Wolstenholme AJ. GLC-3: a novel fipronil and BIDN-sensitive, but picrotoxinin-insensitive, L-glutamate-gated chloride channel subunit from Caenorhabditis elegans. Br J Pharmacol. 2001;132(6):1247-54

33. Hu, P. J. (2007). Dauer. WormBook: 1-19.

34. Hung WL, Wang Y, Chitturi J, Zhen M. A Caenorhabditis elegans developmental decision requires insulin signaling-mediated neuronintestine communication. Development. 2014;141(8):1767-79.

35. Kaplan RE, Chen Y, Moore BT, Jordan JM, Maxwell CS, Schindler AJ, Baugh LR. dbl-1/TGF-beta and daf-12/NHR signaling mediate cell-nonautonomous effects of daf-16/FOXO on starvation-induced developmental arrest. PLoS Genet. 2015;11(12):e1005731.

36. Kimura KD, Riddle DL, Ruvkun G. The C. elegans DAF-2 insulin-like receptor is abundantly expressed in the nervous system and regulated by nutritional status. Cold Spring Harb Symp Quant Biol. 2011;76:113-20.

37. Laing ST, Ivens A, Butler V, Ravikumar SP, Laing R, Woods DJ, Gilleard JS. The transcriptional response of Caenorhabditis elegans to Ivermectin exposure identifies novel genes involved in the response to reduced food intake. PLoS One. 2012;7(2):e31367.

38. Langmead B, Trapnell C, Pop M, Salzberg SL. Ultrafast and memory-efficient alignment of short DNA sequences to the human genome. Genome Biol. 2009;10(3):R25

39. Lans $H$, Jansen $G$. Multiple sensory $G$ proteins in the olfactory, gustatory and nociceptive neurons modulate longevity in Caenorhabditis elegans. Dev Biol. 2007;303(2):474-82.

40. Li W, Kennedy SG, Ruvkun G. daf-28 encodes a C. elegans insulin superfamily member that is regulated by environmental cues and acts in the DAF-2 signaling pathway. Genes Dev. 2003;17(7):844-58.

41. Libert S, Zwiener J, Chu X, Vanvoorhies W, Roman G, Pletcher SD. Regulation of Drosophila life span by olfaction and food-derived odors. Science. 2007;315(5815):1133-7.

42. Lin K, Dorman JB, Rodan A, Kenyon C. daf-16: an HNF-3/forkhead family member that can function to double the life-span of Caenorhabditis elegans. Science. 1997;278(5341):1319-22.

43. Link CD, Cypser JR, Johnson CJ, Johnson TE. Direct observation of stress response in Caenorhabditis elegans using a reporter transgene. Cell Stress Chaperones. 1999;4(4):235-42.

44. Maxwell CS, Antoshechkin I, Kurhanewicz N, Belsky JA, Baugh LR. Nutritional control of mRNA isoform expression during developmental arrest and recovery in C. elegans. Genome Res. 2012;22(10):1920-9.

45. McColl G, Rogers AN, Alavez S, Hubbard AE, Melov S, Link CD, Bush Al, Kapahi $P$, Lithgow GJ. Insulin-like signaling determines survival during stress via posttranscriptional mechanisms in C. elegans. Cell Metab. 2010;12(3):260-72.

46. Moore BT, Jordan JM, Baugh LR. WormSizer: high-throughput analysis of nematode size and shape. PLoS One. 2013;8(2):e57142.

47. Morris JZ, Tissenbaum HA, Ruvkun G. A phosphatidylinositol-3-OH kinase family member regulating longevity and diapause in Caenorhabditis elegans. Nature. 1996;382(6591):536-9.

48. Mylenko M, Boland S, Penkov S, Sampaio JL, Lombardot B, Vorkel D, Verbavatz $J M$, Kurzchalia TV. NAD+ is a food component that promotes exit from Dauer diapause in Caenorhabditis elegans. PLoS One. 2016:11(12):e0167208.

49. Ogg S, Paradis S, Gottlieb S, Patterson Gl, Lee L, Tissenbaum HA, Ruvkun G. The fork head transcription factor DAF-16 transduces insulin-like metabolic and longevity signals in C. elegans. Nature. 1997;389(6654):994-9.

50. Patel DS, Garza-Garcia A, Nanji M, McElwee JJ, Ackerman D, Driscoll PC, Gems D. Clustering of genetically defined allele classes in the Caenorhabditis elegans DAF-2 insulin/IGF-1 receptor. Genetics. 2008;178(2):931-46.

51. Pierce SB, Costa M, Wisotzkey R, Devadhar S, Homburger SA, Buchman AR, Ferguson KC, Heller J, Platt DM, Pasquinelli AA, Liu LX, Doberstein SK, Ruvkun G. Regulation of DAF-2 receptor signaling by human insulin and ins-1, a member of the unusually large and diverse $C$. elegans insulin gene family. Genes Dev. 2001;15(6):672-86.

52. Pino, EC, Webster, CM, Carr, CE, Soukas, AA. Biochemical and High Throughput Microscopic Assessment of Fat Mass in Caenorhabditis Elegans. J Vis Exp. 2013;73:e50180. https://doi.org/10.3791/50180.
53. Puig O, Marr MT, Ruhf ML, Tjian R. Control of cell number by Drosophila FOXO: downstream and feedback regulation of the insulin receptor pathway. Genes Dev. 2003;17(16):2006-20.

54. Riddle DL, Swanson MM, Albert PS. Interacting genes in nematode dauer larva formation. Nature. 1981;290(5808):668-71.

55. Riera CE, Tsaousidou E, Halloran J, Follett P, Hahn O, Pereira MMA, Ruud LE, Alber J, Tharp K, Anderson CM, Bronneke H, Hampel B, Filho CDM, Stahl A, Bruning JC, Dillin A. The sense of smell impacts metabolic health and obesity. Cell Metab. 2017;26(1):198-211.e5.

56. Robinson MD, McCarthy DJ, Smyth GK. edgeR: a bioconductor package for differential expression analysis of digital gene expression data. Bioinformatics. 2010;26(1):139-40.

57. Sanford T, Golomb M, Riddle DL. RNA polymerase II from wild type and alpha-amanitin-resistant strains of Caenorhabditis elegans. J Biol Chem. 1983:258(21):12804-9.

58. Sawin ER, Ranganathan R, Horvitz HR. C. elegans locomotory rate is modulated by the environment through a dopaminergic pathway and by experience through a serotonergic pathway. Neuron. 2000;26(3):619-31.

59. Sjostrom L, Garellick G, Krotkiewski M, Luyckx A. Peripheral insulin in response to the sight and smell of food. Metabolism. 1980;29(10):901-9.

60. Stadler M, Fire A. Conserved translatome remodeling in nematode species executing a shared developmental transition. PLoS Genet. 2013:9(10):e1003739.

61. Sulston JE, Horvitz HR. Post-embryonic cell lineages of the nematode, Caenorhabditis elegans. Dev Biol. 1977;56(1):110-56.

62. The Gene Ontology C. Expansion of the Gene Ontology knowledgebase and resources. Nucleic Acids Res. 2017:45(D1):D331-8.

63. Vassilatis DK, Arena JP, Plasterk RH, Wilkinson HA, Schaeffer JM, Cully DF, Van der Ploeg LH. Genetic and biochemical evidence for a novel avermectin-sensitive chloride channel in Caenorhabditis elegans. Isolation and characterization. J Biol Chem. 1997;272(52):33167-74.

64. Weinkove D, Halstead JR, Gems D, Divecha N. Long-term starvation and ageing induce AGE-1/PI 3-kinase-dependent translocation of DAF-16/FOXO to the cytoplasm. BMC Biol. 2006;4:1.

65. Zaslaver A, Baugh LR, Sternberg PW. Metazoan operons accelerate recovery from growth-arrested states. Cell. 2011;145(6):981-92.

\section{Ready to submit your research? Choose BMC and benefit from:}

- fast, convenient online submission

- thorough peer review by experienced researchers in your field

- rapid publication on acceptance

- support for research data, including large and complex data types

- gold Open Access which fosters wider collaboration and increased citations

- maximum visibility for your research: over $100 \mathrm{M}$ website views per year

At BMC, research is always in progress.

Learn more biomedcentral.com/submissions 